\title{
Rule change curbs grants to European labs
}

Munich. European-level laboratories may no longer be able to receive grants from the European Commission (EC) for scientists from European Union (EU) member states to use their large-scale facilities, under a new interpretation of the rules governing the allocation of EU research funds.

This new interpretation, which is intended to focus support on EU scientists using national facilities in another state, may have wider implications, as the commission is discussing whether it should also apply to all guest scientists wishing to work at any European-level laboratory.

The European Molecular Biology Laboratory (EMBL), which has its main laboratory in Heidelberg and two outstations at synchrotron facilities in Grenoble and Hamburg, is the first to be affected by the apparent change in the commission's philosophy.

EMBL has been informed unofficially that grants received under the Human Capital and Mobility programme of the EU's third Framework programme, which ran from 1990 to 1994, will not be awarded under the equivalent programme in the fourth Framework, called Training and Mobility of Researchers (TRM).

The laboratory had received nearly ECU3 million (US\$3.85 million) from the third Framework to improve research equipment for visitors using neutron beams at its outstations, and to equip a supercomputer centre associated with its main laboratory.

The funds were also used for a major visitor programme for EU scientists. "If the money is not renewed, it will be a great loss," says the Grenoble outstation director, Steve Cusack.

The basic philosophy of the new TRM programme has not changed from that of its predecessor, namely to promote the movement of researchers between EU countries. But some details have changed in the way that funds are used. Equipment costs, for example, are not being financed this time. And all applications will be considered by a single multidisciplinary committee, rather than by a series of scientific assessment committees divided along disciplinary lines.

The members of this new committee, which met in July to make its recommendations for the first round of the TRM Large Scale Facilities programme - the part of the overall programme designed to support work at large research facilities - have been told that they should seek to maximize the access of European scientists to European facilities in general, at both national and European levels, as well as judge applications on their scientific merit.

According to Allan Mackintosh, the committee's chairman who is a solid-state physicist from the University of Copenhagen, since most EU member states are members of EMBL (only Portugal and Luxembourg are not), they already have access to its outstations. As a result, EMBL's bid for support was not judged to be a cost-effective way of using the TRM budget.

"It is not true to say that European-level laboratories are not eligible," says Mackin-

\section{Chinese agree to eugenics discussion}

London. The International Genetics Federation (IGF) has withdrawn a threat to abandon its choice of the Chinese capital Beijing for its next five-yearly Congress, following an agreement by the Chinese organizing committee that the meeting will include a symposium on eugenics.

The IGF was considering abandoning Beijing for the 1998 International Genetics Congress in protest at the Chinese government's decision to introduce a new 'eugenic' law designed to reduce 'inferior births' by forbidding people with inherited diseases from marrying (see Nature 372, $123 ; 1994)$.

The law, which came into effect on 1 June this year, is a watered-down version of a bill that was heavily criticized by the international scientific community when proposed in January 1994. Members of the IGF's executive committee had voted in March to find an alternative venue unless their Chinese hosts agreed to hold "a full discussion of eugenics" during the 1998 congress.

In a statement issued last week, A. J. F. Griffiths, secretary to the IGF, said this request had now been met and the congress would therefore proceed as planned. The eugenics session, he added, will cover a range of scientific and ethical topics. "It is expected that speakers will include experts in various areas such as history, ethics, population genetics and medical genetics."

David Smith, of the University of Birmingham and president of the IGF, says convincing the Chinese organizers to set aside time for the symposium had not been easy. A key issue for the Chinese scientists had been their concern that the symposium might be used as an occasion for attacks on the government.

But Smith adds that the Chinese authorities have promised not to interfere in the running of the programme, or to stop any delegate from attending on political grounds. The genetics congress, which was first held in London in 1899, has had to change its advertised venue just once in the past. The 1939 congress opened in Edinburgh, Scotland a few days before war broke out against the original host, Nazi Germany.

Ehsan Masood tosh. "It's just that they couldn't compete on this criterion [of cost-effectiveness]."

The Large Scale Facilities programme has been allocated a total of ECU110 million in the fourth Framework programme, of which ECU72 million is being distributed in this round. Even so, only about 40 per cent

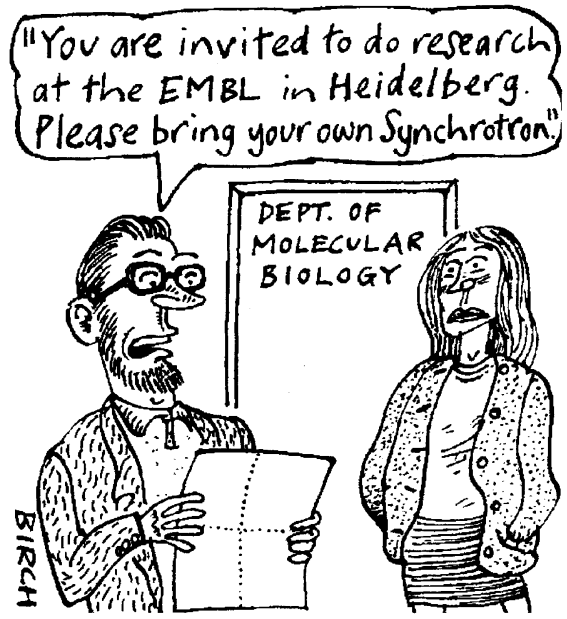

of the 200-odd applications received, whose general standard was high, could be funded, says Mackintosh. A second call for proposals will be made in 1997 , prior to the distribution of the remaining funds.

The commission is also very unhappy about frequent leaks from TRM programme committees, despite the fact that their members are required to pledge confidentiality. This time the source of information leaked to EMBL has been identified, and a commission spokesman says that the individual concerned will not be asked to sit on any future EC committees

A formal confirmation by the commission of the TRM Large Scale Programme committee's recommendations is due later this month. "If a formal decision is taken that the money will not be available in future, we will have to move cash from elsewhere [in EMBL's budget]," says Barton Dodd, the laboratory's administrative director. "It will have serious implications for us."

EMBL is already experiencing difficulty in raising funds that it is seeking from its member states to support an expanded programme in the period 1996-2000, including growth in its visitor programme.

The commission's new interpretation of the TRM programme rules may have even wider implications. According to the German delegation, the TRM programme committee, which is made up of two delegates from each EU member state, is considering whether to disallow, or at least 'deprioritize', bids for funding from the human mobility section of the TRM programme for scientists wishing to work at EMBL and other European facilities. This issue will be discussed by the committee in December.

Alison Abbott 